Revista Universo Contábil, ISSN 1809-3337

FURB, v. 5, n.4, p. 134-151, out./dez., 2009

doi:10.4270/ruc.2009435

Disponível em www.furb.br/universocontabil

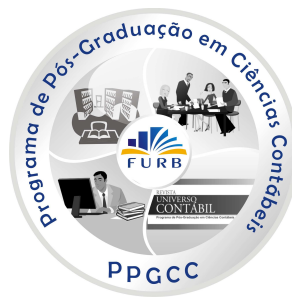

\title{
O CONCEITO, O RECONHECIMENTO E A VALORAÇÃO DOS ACTIVOS PÚBLICOS: ESPECIAL MENÇÃO A PORTUGAL*
}

\author{
O CONCEITO, O RECONHECIMENTO E A VALORIAZAÇÃO DOS ATIVOS \\ PÚBLICOS: ESPECIAL MENÇÃO A PORTUGAL
}

\section{THE CONCEPT, RECOGNITION AND MEASUREMENT OF PUBLIC ASSETS: SPECIAL MENTION TO PORTUGAL}

\author{
Susana Catarino Rua \\ Mestre em Ciências Empresariais - Especialização em Contabilidade \\ Professora da Escola Superior de Gestão do Instituto Politécnico do Cávado e do Ave \\ Endereço: Urb. Quinta da Formiga, Ed. Panorâmico II - Lote 3, Arcozelo \\ CEP: 4750-117 - Barcelos - Portugal \\ E-mail: srua@ipca.pt \\ Telefone: +351253802260
}

\section{RESUMO}

Com a reforma da Contabilidade Pública em Portugal, e consequentemente a implementação de planos de contabilidade pública sectoriais, a contabilidade patrimonial ganhou importância neste sistema contabilístico, sendo necessário definir a composição e o valor do património de cada entidade pública. A classificação dos elementos patrimoniais como activos tornou-se uma das preocupações destas entidades, sendo necessário definir critérios precisos para o seu reconhecimento e valoração. Estes critérios juntamente com um conjunto de conceitos dos elementos das demonstrações financeiras fazem parte da estrutura conceptual tão necessária para a Contabilidade Pública em Portugal. Partindo do conceito de activo das empresas e dos seus critérios de reconhecimento, e atendendo às particularidades das entidades públicas poderemos definir um conceito de activo público bem como critérios para o seu reconhecimento e para a sua valoração, aos quais um elemento deverá necessariamente

Artigo recebido em 22.10.2007. Revisado por pares em 28.11.2007. Reformulado em 20.01.2008. Recomendado em 28.01.2008 por Ilse Maria Beuren (Editora). Publicado em 30.11.2009. Organização responsável pelo periódico: FURB. 
obedecer para que possa constar no balanço de uma determinada entidade pública, compondo dessa forma o seu património.

Palavras-chave: Contabilidade Pública. Activo. Demonstrações financeiras.

\section{RESUMO}

Com a reforma da Contabilidade Pública em Portugal, e conseqüentemente a implementação de planos de contabilidade pública setoriais, a contabilidade patrimonial ganhou importância neste sistema contábil, sendo necessário definir a composição e o valor do patrimônio de cada entidade pública. A classificação dos elementos patrimoniais como ativos tornou-se uma das preocupações destas entidades, sendo necessário definir critérios precisos para o seu reconhecimento e valoração. Estes critérios, juntamente com um conjunto de conceitos dos elementos das demonstrações financeiras, fazem parte da estrutura conceitual tão necessária para a Contabilidade Pública em Portugal. Partindo do conceito de ativo das empresas e dos seus critérios de reconhecimento, e atendendo às particularidades das entidades públicas pode-se definir um conceito de ativo público bem como critérios para o seu reconhecimento e para a sua valoração, nos quais um elemento deverá necessariamente ser obedecido para que possa constar no balanço de uma entidade pública, compondo dessa forma o seu património.

Palavras-chave: Contabilidade Pública. Activo. Demonstrações financeiras.

\section{ABSTRACT}

As a result of the Governmental Accounting reform in Portugal, and consequently the implementation of sectorial governmental accounting plans, the patrimonial accounting received importance in this accounting system, being needed to define the elements and the value of the patrimony of each public entity. The classification of the patrimonial elements as assets became one of the concerns of those entities, being necessary to define accurate criteria for their recognition and measurement. These criteria, with a group of concepts of the elements of the financial statements, are part of the conceptual framework necessary for the Governmental Accounting in Portugal. From the concept of asset of the companies and from their recognition criteria, and considering the particularities of the public entities, we will be able to define a concept of public asset, as well as criteria, for its recognition and its measurement, to which an element must obey so as to be reported in the balance-sheet of a certain public entity, and in that way being part of its patrimony.

Keywords: Governmental accounting. Assets. Financial statements.

\section{INTRODUÇÃO}

Com a internacionalização da economia e consequentemente a necessidade de harmonização contabilística internacional, os sistemas de normalização contabilísticos nacionais sofreram alterações não só no âmbito empresarial como também público.

No âmbito público, a contabilidade patrimonial é relativamente recente, e resulta da reforma da Contabilidade Pública em Portugal, ganhando importância inquestionável desde a implementação do Plano Oficial de Contabilidade Pública (POCP) e restantes planos públicos sectoriais. 
Assim, mapas como o Balanço e a Demonstração de Resultados começam a desempenhar, na Contabilidade Pública, um papel importante enquanto demonstrações financeiras capazes de fornecer informação útil para a tomada de decisões.

Não obstante, os planos públicos apresentam lacunas do ponto de vista conceptual, não incluindo um completo e adequado conjunto de conceitos teóricos subjacentes à preparação e apresentação das demonstrações financeiras, como é o caso do conceito, critérios de reconhecimento e valoração dos elementos das demonstrações financeiras. Constata-se assim a urgência em definir uma adequada estrutura conceptual para este sistema contabilístico.

A definição de uma estrutura conceptual para a Contabilidade Pública, e especificamente o que se pretende aqui tratar, a definição do conceito de activo, seus critérios de reconhecimento e valoração, poderá partir duma análise dos conceitos de âmbito empresarial e da sua aplicabilidade ao âmbito público, atendendo às especificidades da Contabilidade Pública, caminho que se seguiu neste trabalho.

Este trabalho divide-se nos seguintes capítulos: num capítulo inicial analisa-se o activo enquanto elemento das demonstrações financeiras públicas, em resultado da evolução da normalização da Contabilidade Pública em Portugal, bem como o seu enquadramento enquanto elemento da necessária estrutura conceptual para a Contabilidade Pública; num outro capítulo, procede-se à análise do conceito de activo; e, nos dois últimos capítulos, estudam-se os critérios de reconhecimento e os critérios de valoração dos activos, partindo do definido por vários organismos nacionais e internacionais.

\section{OS ACTIVOS PÚBLICOS FACE À EVOLUÇÃo DA NORMALIZAÇÃO DA CONTABILIDADE PÚBLICA EM PORTUGAL E À NECESSIDADE DE UMA ESTRUTURA CONCEPTUAL}

\subsection{A Evolução da Normalização da Contabilidade Pública em Portugal}

Em virtude do processo de globalização e internacionalização da economia, a evolução da normalização da Contabilidade tornou-se imprescindível para o alcance de uma harmonização a nível internacional. Essa evolução da normalização não se fez sentir apenas na Contabilidade de âmbito empresarial mas também no âmbito público. Para essa evolução contribuíram também as necessidades de informação cada vez mais exigentes por parte dos utilizadores da informação financeira.

Assim, a evolução da Contabilidade Pública em Portugal divide-se em três fases: $1^{\mathrm{a}}$ Fase - Inicial: Contabilidade Pública Tradicional; $2^{\mathrm{a}}$ Fase - Transitória: Reforma da Contabilidade Pública; $3^{\text {a }}$ Fase - Actual: Implementação de Planos de Contabilidade Pública.

$\mathrm{Na} 1^{a}$ fase a Contabilidade Pública era chamada de contabilidade do orçamento, controlando as receitas e despesas através da análise da execução do orçamento, verificando a sua legalidade, por isso tinha por objectivos: a execução do orçamento, o controlo da legalidade e a prestação de contas.

A Contabilidade Pública tradicional caracterizava-se por registar movimentos de tesouraria, isto é, apenas registava recebimentos e pagamentos, não fazendo registos numa óptica patrimonial mas sim unicamente financeira, utilizando para o efeito o método de registo unigráfico. Uma vez que a óptica patrimonial não estava presente, o Balanço também não era elaborado e portanto, ainda não podíamos falar em elementos activos.

Contudo, em resultado de alguns factores conjunturais, juntamente com essa necessidade de normalização da Contabilidade Pública em Portugal, desencadeou-se uma Reforma da Administração Financeira do Estado, passando-se para a segunda fase da evolução da Contabilidade Pública em Portugal. Esta reforma desenvolveu-se através de um conjunto de diplomas:

a) Lei $\mathrm{n}^{\circ} 8 / 90$, de 20 de Fevereiro, que estabelece as bases da Contabilidade Pública; 
b) Lei $n^{\circ}$ 6/91, de 20 de Fevereiro - Lei de Enquadramento Orçamental, que vem reformular o sistema de execução orçamental, sendo revogada, em 20 de Agosto de 2001, pela Lei $\mathrm{n}^{\circ}$ 91/2001 que instituiu o novo enquadramento orçamental;

c) Decreto-Lei $n^{\circ}$ 155/92, de 28 de Julho, que fixa o novo Regime da Administração Financeira do Estado.

Com esta Reforma, a Contabilidade Pública passa a ter objectivos orientados para o fornecimento de informação útil para a tomada de decisões dos seus utilizadores e para a análise financeira do uso e destino dos fundos públicos, com base em critérios de economia, eficiência e eficácia. Nesta fase a contabilidade de caixa é reestruturada e surge a contabilidade de compromissos, permitindo uma adequada gestão e controlo orçamentais.

Em conformidade com o $\operatorname{art}^{\circ} 45^{\circ}$ de Decreto-Lei $n^{\circ} 155 / 92$, de 28 de julho, nesta fase da Contabilidade Pública, os organismos autónomos, enquanto regime excepcional, tinham de utilizar uma contabilidade enquadrada no Plano Oficial de Contabilidade (POC), ou mesmo criar os seus próprios planos, ou seja, deveriam elaborar uma contabilidade patrimonial, utilizando como método de registo a digrafia, e também, de acordo com a Resolução 1/93 do Tribunal de Contas, uma contabilidade orçamental e uma contabilidade analítica. Além disso, estes organismos deveriam aplicar uma contabilidade de especialização do exercício, uma contabilidade de caixa e uma contabilidade de compromissos.

Como os organismos autónomos eram um regime excepcional, então dizemos que a contabilidade patrimonial, nesta etapa, só era aplicada excepcionalmente por alguns organismos. Assim, neste período apenas algumas entidades, as enquadradas nesse regime excepcional, se deparavam com a "figura de activo" na sua contabilidade.

Numa terceira fase da Contabilidade Pública em Portugal, e para colmatar as diferenças entre os planos específicos a certas actividades que entretanto foram surgindo, foi aprovado o Plano Oficial de Contabilidade Pública (POCP), pelo Decreto-Lei no 232/97, de 3 de setembro, que constitui um importante passo na normalização da Contabilidade Pública portuguesa. O POCP caracteriza-se essencialmente por reunir os três sistemas de contabilidade, a orçamental, a patrimonial e a analítica, e por aplicar como método de registo a digrafia.

Nesta fase, destaca-se também a criação, em 1998, da Comissão de Normalização Contabilística da Administração Pública (CNCAP), organismo responsável pela normalização da Contabilidade Pública em Portugal. Entretanto, desde a publicação do POCP, e com a criação da CNCAP, foram-se tomando medidas com vista à criação de planos públicos sectoriais, descendentes desse plano, que atendam às especificidades das entidades a que se destinam. Assim, desde 1999, foram aprovados os seguintes planos públicos sectoriais:

a) Plano Oficial de Contabilidade das Autarquias Locais (POCAL), aprovado pelo Decreto-Lei $\mathrm{n}^{\mathrm{o}} 54$ - A/99, de 22 de fevereiro;

b) Plano Oficial de Contabilidade para o Sector da Educação (POC-EDU), aprovado pela Portaria $\mathrm{n}^{\circ}$ 794/2000, de 20 de setembro;

c) Plano Oficial de Contabilidade para o Ministério da Saúde (POC-MS), aprovado pela Portaria $n^{\circ} 898 / 2000$, de 28 de setembro;

d) Plano Oficial de Contabilidade das Instituições do Sistema de Solidariedade e Segurança Social (POC-ISSSS), aprovado pelo Decreto-Lei no 12/2002, de 25 de janeiro.

Para além destes planos públicos sectoriais destaca-se ainda, em 2000, a aprovação do Cadastro e Inventário dos Bens do Estado (CIBE), pela Portaria n ${ }^{\circ}$ 671/2000, de 17 de abril, que define os "diferentes critérios de valorimetria para efeitos de elaboração do Inventário dos bens móveis, veículos e imóveis" (CARVALHO; ALVES, 2006, p. 11).

Uma vez aprovados os planos sectoriais de Contabilidade Pública, e introduzida definitivamente a Contabilidade Patrimonial, o mapa elaborado pela Contabilidade Pública 
tradicional - a Conta de Gerência, deixa de responder às necessidades informativas dos seus utilizadores, e as entidades passam a ser obrigadas a elaborar, entre outros mapas contabilísticos, o Balanço, constituído por vários elementos, nomeadamente pelos activos.

A "figura de activo", passa assim a estar presente em todas as entidades obrigadas a aplicar a contabilidade patrimonial, isto é, obrigadas a aplicar um dos planos públicos. Portanto, a "figura de activo" é, na actualidade, imprescindível na elaboração das contas das entidades sujeitas à Contabilidade Pública, isto é, das entidades do sector público administrativo.

\subsection{Os Activos Públicos enquanto Elemento de uma Estrutura Conceptual}

Como vimos com a evolução da normalização da Contabilidade Pública em Portugal, foram aprovados um conjunto de planos públicos. Contudo, esses planos pecam por não incluírem um completo e adequado suporte teórico, isto é, uma estrutura conceptual, o que se traduz em dificuldades na sua aplicação, nomeadamente na classificação dos elementos patrimoniais em "massas".

Para além disso, com a evolução dos objectivos da Contabilidade Pública, direccionados para o fornecimento de informação útil para a tomada de decisões dos seus utilizadores, tornou-se cada vez mais urgente a definição de um quadro conceptual como complemento ao processo de normalização deste sistema contabilístico.

No âmbito empresarial, em Portugal, o problema das lacunas conceptuais do Plano Oficial de Contabilidade (POC), foram ultrapassadas com a aprovação, pela Comissão de Normalização Contabilística (CNC), em julho de 2007, do novo Sistema de Normalização Contabilística (SNC), que inclui uma Estrutura Conceptual para a contabilidade de âmbito empresarial. Uma estrutura conceptual pode ser definida como um adequado conjunto de conceitos teóricos subjacentes à preparação e apresentação das demonstrações financeiras (IASB, 1989, §1), que seja capaz de orientar a interpretação e aplicação das normas contabilísticas.

Então podemos afirmar que a estrutura conceptual para a Contabilidade Pública é um complemento à normalização da Contabilidade Pública, imprescindível para a aplicação das normas com base em fundamentos teóricos sustentáveis, permitindo a sua aplicação mais consistente, facilitando a interpretação das demonstrações financeiras e potenciando assim a comparabilidade da informação.

A definição de uma estrutura conceptual deve seguir um itinerário lógico-dedutivo, seguido pelos países anglo-saxónicos, e ser composta pelos seguintes elementos: utilizadores da informação financeira e suas necessidades de informação; objectivos da informação financeira; características qualitativas da informação financeira; elementos das demonstrações financeiras: conceito, reconhecimento e valoração (ou mensuração); conceito de capital e manutenção do capital; princípios contabilísticos.

Vemos assim que, de entre os elementos que compõem uma estrutura conceptual, destacam-se os elementos das demonstrações financeiras, seu conceito e definição de critérios de reconhecimento e valoração; desses elementos salientam-se aqui os activos públicos, alvo de análise neste trabalho.

Dizemos então que "a definição dos elementos das demonstrações financeiras é consequência dos objectivos da informação financeira e deve interpretar-se no âmbito das características qualitativas" (AECA, 1999, §190), contribuindo para o cumprimento desses objectivos e simultaneamente para a satisfação das necessidades dos seus utilizadores.

Como vimos, em virtude das lacunas conceptuais apresentadas nos planos contabilísticos, e para que seja possível uma perfeita normalização e harmonização contabilística, é necessário que se defina uma estrutura conceptual para a Contabilidade 
Pública em Portugal, que atenda às particularidades deste sistema contabilístico, que lhe esteja subjacente e que permita uma melhor compreensão e harmonia de conceitos e princípios.

\section{CONCEITO DE ACTIVO}

\subsection{Enquadramento do Conceito de Activo nos Normativos Internacionais de Âmbito Empresarial}

Atribuir uma definição de activo tem sido alvo de preocupação por parte de diversos autores e também de diversos organismos nacionais e internacionais. Na verdade, a inexistência de um conceito de activo previamente estabelecido poderá causar controvérsias no reconhecimento dos elementos como activos, por parte de diferentes entidades.

Usualmente define-se activo, do ponto de vista empresarial, como o conjunto dos bens e direitos de uma empresa. Nessa perspectiva, Jaime Lopes de Amorim (in FREITAS, 2000, p. 4-5) define activo como "o conjunto de todos os recursos que a empresa tem à sua disposição e por meio do funcionamento ou movimentação dos quais ela procura realizar todos os seus objectivos".

Diversos organismos de cariz nacional e internacional apresentam o conceito de activo nas suas normas ou nas suas estruturas conceptuais. O Quadro 1 apresenta definições de activo, atendendo ao âmbito empresarial, apresentadas por alguns desses organismos.

\begin{tabular}{|c|l|}
\hline Entidade & \multicolumn{1}{c|}{ Conceito de Activo } \\
\hline $\begin{array}{c}\text { IASB } \\
(1989, \text { alínea a }) \S 49)\end{array}$ & $\begin{array}{l}\text { "Recurso controlado pela empresa em resultado de acontecimentos } \\
\text { passados e do qual se espera que fluam para a empresa benefícios } \\
\text { económicos futuros". }\end{array}$ \\
\hline $\begin{array}{c}\text { FASB } \\
(1985, \S 25)\end{array}$ & $\begin{array}{l}\text { "Provável benefício económico futuro obtido ou controlado por uma } \\
\text { determinada entidade em resultado de uma transacção ou evento } \\
\text { passado". }\end{array}$ \\
\hline $\begin{array}{c}\text { ASB } \\
\text { por uma entidade em resultado de transacções ou eventos passados". }\end{array}$ \\
\hline $\begin{array}{c}\text { AECA } \\
(1999, \text { cap. } 4)\end{array}$ & $\begin{array}{l}\text { "Recurso controlado economicamente pela entidade como resultado de } \\
\text { acontecimentos passados, do qual seja provável a obtenção, no futuro, } \\
\text { de rendimentos para a entidade". }\end{array}$ \\
\hline $\begin{array}{l}\text { CNC } \$ 196) \\
\text { "Recurso controlado pela entidade como resultado de acontecimentos } \\
\text { passados e do qual se espera que fluam para a entidade benefícios } \\
\text { económicos futuros". }\end{array}$ \\
\hline
\end{tabular}

Quadro 1 - Conceito de Activo: âmbito empresarial

Fonte: elaboração própria.

Todos os organismos mencionados no Quadro 1 definem os activos atendendo aos benefícios económicos futuros que eles produzem para a entidade. Conforme refere o International Accounting Standards Board (IASB) (1989), no $\$ 53$ da sua estrutura conceptual, os benefícios económicos futuros mencionados no conceito de activo devem ser interpretados como "o potencial de contribuir, directa ou indirectamente, para o fluxo de caixa e de equivalentes de caixa para a empresa". Na verdade, "a convertibilidade dos activos em dinheiro, através da geração de fluxos de caixa ou seus equivalentes, é a característica fundamental desta classe de bens" (FREITAS, 2007, p. 4), referida nas definições apresentadas no Quadro 1.

Em virtude do exposto, para um elemento poder ser reconhecido como activo tem de possuir capacidade de produzir benefícios económicos futuros para a entidade. Isto significa que a vida de um elemento enquanto activo aparece limitada por essa capacidade de produzir benefícios económicos futuros, portanto quando esta capacidade desaparecer "o activo 
converte-se num custo, numa redução de recursos ou numa perda" (YEBRA CEMBORAIN, 2000, p. 202). Essa perda de capacidade de gerar benefícios económicos pode dever-se quer a questões inerentes ao próprio activo, quer também a razões inerentes à capacidade global da entidade e já não específica do activo.

Ainda em conformidade com o Quadro 1, e indo ao encontro do mencionado por Cardão-Pito (2007, p. 7), todas as definições têm em comum três elementos: a) benefícios económicos futuros/rendimentos; b) controlo; c) acontecimentos/eventos passados. Tendo em conta estes três elementos, e conforme mencionado por Rua e Carvalho (2006, p. 155), e também segundo o Financial Accounting Standards Board (FASB) (1985, §26), podemos atribuir aos activos três características básicas ou essenciais, resultantes do seu conceito, a saber:

a) controlo económico - o activo deverá ser controlado pela entidade, para que esta possa dispor dos rendimentos produzidos por esse activo;

b) probabilidade de obtenção de rendimentos futuros - os activos devem possuir a capacidade de contribuírem por si, ou conjuntamente com outros activos, para a obtenção de rendimentos, fluxos de tesouraria, para a entidade que os controla economicamente;

c) resultado de factos passados - se o elemento não resultar de factos passados mas sim supuser expectativas de transacções a realizar, este não poderá ser reconhecido como um activo. Conforme Freitas (2007, p. 6) é este aspecto que "diferencia os elementos que já são activos, dos que potencialmente poderão vir a sê-lo".

Para além destas características básicas, a Asociación Española de Contabilidad y Administración de Empresas (AECA) (1999, §§202-208), no seu marco conceptual para a informação financeira (empresarial), apresenta um outro conjunto de características dos activos, que designamos de não básicas, a saber:

a) o prazo pelo qual se espera que um activo produza rendimentos deve ser submetido a revisão;

b) a forma como um activo pode surgir na entidade é diversa, mas a sua existência é independente do modo como este surge;

c) o corpo físico não é essencial para a existência de um activo;

d) a propriedade legal ou jurídica de um elemento não é necessária para a sua classificação como activo; o que realmente interessa é que a entidade exerça um controlo económico do bem e, portanto, possa dispor dos benefícios produzidos por aquele activo.

Assim, um elemento para ser reconhecido como activo, no âmbito empresarial, deverá, em primeiro lugar, preencher o seu conceito, e possuir um conjunto de características básicas, conforme apresentado anteriormente.

\subsection{Análise da Aplicabilidade do Conceito de Activo ao Âmbito Público}

Tendo em mente o conceito de activo definido no âmbito empresarial, a questão reside em analisar se esse conceito se poderá aplicar à Contabilidade Pública, ou se, pelo contrário, esta requer uma interpretação diferente ou mesmo um conceito distinto.

A primeira questão que se nos coloca é relativamente aos benefícios económicos futuros referidos na definição de activo no âmbito empresarial. Na Contabilidade Pública, os activos são vistos em função do potencial de serviços que podem prestar, e já não (apenas) dos rendimentos que advêm do mesmo. Portanto, os benefícios económicos futuros, da definição de activo, devem ser interpretados, na Contabilidade Pública, em resultado da quantidade e qualidade de serviços prestados por esse activo. 
Então, não podemos dizer que as definições de âmbito empresarial, apresentadas anteriormente no Quadro 1, não se aplicam aos activos públicos, mas sim que possuem no âmbito público uma diferente interpretação, o que implica que se proceda a alguns ajustes às mesmas. A AECA (2001, §194), no seu marco conceptual para a Contabilidade Pública, define activo do seguinte modo: "um recurso controlado pela entidade como resultado de factos passados, do qual seja possível a prestação futura de serviços públicos ou a obtenção de rendimentos".

Comparando esta definição de activo público com as definições apresentadas no Quadro 1, vemos que aqui foi acrescentada a "prestação futura de serviços públicos" por parte do activo, e já não apenas a obtenção de rendimentos ou de benefícios económicos futuros, referidos nas anteriores definições de âmbito empresarial. De forma similar, a International Federation of Accountants (IFAC) (2000) apresenta uma definição igual à apresentada pelo International Accounting Standards Board (IASB) (1989), mas acrescenta nas características de activo público o seu potencial de prestar serviços.

Portanto, na Contabilidade Pública, a aptidão de um elemento enquanto activo é vista pela sua capacidade de prestar serviços. Esta capacidade de prestar serviços pode ser interpretada como a aptidão do activo para satisfazer as necessidades dos seus beneficiários, e para contribuir, de uma forma directa ou indirecta, por si só ou juntamente com outros activos, para a concretização dos objectivos da entidade que o reconhece como tal.

$\mathrm{Na}$ Contabilidade Pública, a inexistência de uma contrapartida monetária por parte de um elemento, não é motivo para que o mesmo não seja classificado como activo. Isto faz sentido se atendermos a alguns activos públicos que não produzem quaisquer rendimentos, antes pelo contrário, implicam unicamente despesas de manutenção, mas que mesmo assim são classificados como activos. É, por exemplo, o caso dos bens de domínio público que possuem objectivos de âmbito social, e elevados custos de manutenção, resultando muitas vezes em fluxos de caixa negativos. A este respeito, conforme referido por Brusca Alijarde (2000), não existe consenso quanto à inclusão (ou não) dos bens de domínio público no balanço duma entidade pública, ou se devem ser considerados apenas no seu inventário.

Contudo, se atendermos às especificidades da definição de activo para a Contabilidade Pública, anteriormente referidas, estes elementos deverão ser reconhecidos como activos, apesar de não gerarem rendimentos, desde que possuam capacidade para prestar serviços, preenchendo assim o conceito de activo público. Em concordância com este facto, o POCP classifica estes bens como parte do activo, apresentando para o efeito a conta " 45 - Bens de Domínio Público". A maior problemática na inclusão destes bens no balanço, enquanto activos, reside na sua valoração, questão analisada mais adiante.

Então, podemos concluir, que as definições de activo, de âmbito empresarial, podem aplicar-se à Contabilidade Pública, mas requerem uma diferente interpretação, nomeadamente no que tange aos benefícios económicos futuros resultantes de um activo que devem ser vistos, no âmbito público, não (apenas) em função dos rendimentos que estes proporcionam, mas também, e sobretudo, dos serviços que prestam e da sua capacidade para os continuarem a prestar. Se a aplicação do conceito de activo no âmbito empresarial requer diferente interpretação no âmbito público, que dizer das características básicas de um activo anteriormente apresentadas? Poderão aplicar-se aos activos públicos?

Relativamente à Contabilidade Pública, as características básicas também se aplicam; não obstante, a segunda característica básica dos activos - probabilidade de produzir benefícios económicos futuros, deve ser vista, na Contabilidade Pública, como a capacidade que os activos possuem de prestarem serviços ou de produzirem rendimentos para a entidade.

Relativamente ao controlo de um activo, a AECA (2001) refere que "o reconhecimento de um activo deve realizar-se quando, uma vez cumprida a característica da fiabilidade, se efectue a transacção, de maneira que a entidade adquira o direito a utilizá-lo 
para a sua prestação de serviços ou na obtenção de rendimentos futuros associados ao activo em questão". Relacionado com o referido anteriormente, quanto às características de um activo, o que está aqui em causa não é a sua posse jurídica mas sim o controlo do activo, ao qual, segundo a AECA, se deve de atender no momento do seu reconhecimento.

Portanto, dizemos assim que um elemento deve constar do balanço da entidade que o controla e que, portanto, possua o direito de o utilizar na prestação de serviços, na obtenção de rendimentos e/ou no alcance dos seus objectivos.

Quanto às características não básicas, e também associada ao controlo de um activo, importa referir que a característica que menciona que a posse jurídica de um elemento não é necessária para o classificar como activo, está relacionada com o princípio da substância sobre a forma, não mencionado no POCP. Apesar desse princípio contabilístico não ser referido neste plano, ele está-lhe implícito no tratamento dos bens em regime de leasing, por isso podemos dizer que essa característica não básica também se pode aplicar aos activos públicos.

Tanto esta característica não básica de um activo, como as restantes, também são aplicáveis aos activos das entidades públicas, sendo mesmo referidas, de forma similar, pela AECA (2001) no seu marco conceptual para a informação financeira das entidades públicas. Em suma, podemos dizer que as características dos activos apresentadas no âmbito empresarial podem aplicar-se ao âmbito público desde que se tenha em atenção, como vimos, algumas particularidades inerentes à própria Contabilidade Pública e às entidades a esta sujeitas.

\section{CRITÉRIOS DE RECONHECIMENTO DOS ACTIVOS}

\subsection{Conceito de Reconhecimento}

Podemos definir reconhecimento como o procedimento pelo qual um determinado elemento é incorporado numa demonstração financeira de uma certa entidade, uma vez satisfeita a sua definição e os seus critérios de reconhecimento. Portanto, para o reconhecimento de um activo nas demonstrações financeiras, este deve preencher dois requisitos, a saber:

a) o seu conceito, acompanhado por um conjunto de características que lhe são inerentes; e cumulativamente;

b) os critérios para o seu reconhecimento.

Caso o seu conceito e/ou os critérios de reconhecimento não sejam preenchidos, o elemento não poderá ser reconhecido e constar nas demonstrações financeiras, mas sim deve apenas ser mencionado no anexo às mesmas, podendo num futuro próximo qualificar-se para ser reconhecido, desde que venha a preencher o(s) requisito(s) que estava(m) anteriormente em falta.

\subsection{Critérios de Reconhecimento de um Activo no Âmbito Empresarial}

Tal como o conceito dos elementos das demonstrações financeiras, os seus critérios de reconhecimento também têm sido alvo de análise por parte dos organismos nacionais e internacionais de contabilidade.

O IASB (1989), no §83 da sua estrutura conceptual, de âmbito empresarial, apresenta dois critérios genéricos de reconhecimento de qualquer elemento das demonstrações financeiras, a saber: "for provável que qualquer benefício económico futuro, associado com o elemento, fluirá para, ou de, a empresa; o elemento tiver um custo ou um valor que possa ser quantificado com fiabilidade". 
Especificamente no caso dos activos empresariais, o IASB (1989) menciona, no §89 da sua estrutura conceptual, os seguintes critérios de reconhecimento: "for provável que os benefícios económicos futuros fluam para a empresa; tenha um custo ou um valor que possa ser quantificado com fiabilidade".

A CNC (2007, §87) apresenta os mesmos critérios de reconhecimento referidos pelo IASB (1989, §89). Estes critérios podem ser associados, respectivamente, às características qualitativas da relevância e da fiabilidade. Isto significa que um elemento só é reconhecido se for relevante para a entidade, e também se o seu valor puder ser medido com fiabilidade.

O referido critério da fiabilidade da valoração de um elemento é resultante da necessidade de recurso a estimações para a valoração de certos elementos, ou seja, das próprias condições de incerteza nas quais a entidade se insere. O IASB (1989) refere, no §86 da sua estrutura conceptual, que "o uso de estimativas razoáveis é uma parte essencial da preparação das demonstrações financeiras e não destrói a sua fiabilidade. Quando, porém, uma estimativa razoável não pode ser feita o elemento não é reconhecido no balanço e na demonstração de resultados".

Associadas à relevância e à fiabilidade temos um conjunto de características qualitativas denominadas secundárias que também deverão estar presentes nesta classificação, e que o FASB $(1984, \S 63)$ as classifica como um outro critério de reconhecimento, como é o caso da objectividade, neutralidade, verificabilidade e prudência, entre outras.

\subsection{Análise da Aplicabilidade dos Critérios de Reconhecimento de um Activo ao Âmbito Público}

De forma idêntica ao conceito de activo, a questão que se coloca é se os critérios de reconhecimento de um activo no âmbito empresarial se aplicam ao âmbito público. Como vimos anteriormente, os benefícios económicos futuros devem ser interpretados, na Contabilidade Pública, em função do potencial de prestar serviços, e já não exclusivamente pelos rendimentos associados ao elemento.

Por isso, tendo presentes os critérios genéricos de reconhecimento de qualquer elemento das demonstrações financeiras, que acabamos de referir, podemos dizer que o reconhecimento de um elemento como activo público, deve obedecer aos seguintes critérios:

a) seja provável a sua aplicação no alcance dos objectivos da entidade e na prestação de serviços;

b) o seu valor possa ser medido com fiabilidade.

Estes estão também associados às características da relevância do elemento e da fiabilidade da sua valoração. Se um elemento não puder ser utilizado no alcance dos objectivos da entidade ou na prestação de serviços, mesmo que o seu valor possa ser medido com fiabilidade, este deixa de ser reconhecido como activo, deixando assim de aparecer no Balanço, convertendo-se num custo a evidenciar na Demonstração de Resultados.

Por outro lado, há situações em que se preenche o primeiro critério de reconhecimento de um activo, mas não se consegue medir com fiabilidade o seu valor. Em tais casos o elemento também não deverá ser reconhecido como activo. Portanto, basta que um elemento não preencha um dos critérios de reconhecimento do activo, para deixar de ser classificado como tal. Isto mostra claramente que um elemento uma vez reconhecido como activo não está reconhecido para sempre.

Este aspecto tem que ver com o momento de reconhecimento do elemento. Relativamente a este assunto, o GASB (1990, §3) apresenta três momentos para o reconhecimento, a saber: base de caixa (as transacções devem ser registadas no momento da prestação monetária); base do acréscimo (as transacções devem ser registadas atendendo à 
corrente real dos bens e serviços que representam); base do acréscimo modificado (segue-se uma base de caixa e uma base do acréscimo).

$\mathrm{Na}$ Contabilidade Pública tradicional em Portugal, aplicava-se apenas uma contabilidade de caixa, os elementos eram reconhecidos atendendo "ao momento em que ocorria a respectiva contrapartida monetária" (RUA; CARVALHO, 2006, p. 152). Contudo, em virtude da base de caixa ser incompleta, houve necessidade de introduzir, com a evolução da Contabilidade Pública, as restantes bases (momentos) de reconhecimento.

Em suma, para que um elemento possa ser classificado como activo e incluído no balanço de uma entidade pública, deve preencher o seu conceito, ser relevante para a entidade em causa, quer na prestação de serviços quer no alcance dos objectivos da entidade, e o seu valor deve poder ser medido com fiabilidade.

\section{VALORAÇÃO DOS ACTIVOS}

\subsection{Critérios de Valoração dos Activos - âmbito empresarial}

Valorar ou mensurar um elemento duma demonstração financeira significa determinar o valor pelo qual o elemento deve ser reconhecido nessa demonstração financeira (IASB, 1989, §99; CNC, 2007, §97). A valoração dos activos tem sido alvo de grande polémica nos tempos actuais, não só no âmbito empresarial mas também, e sobretudo, no âmbito público.

No âmbito empresarial, o IASB (1989) apresenta, no §100 da sua estrutura conceptual, quatro critérios de valoração dos activos, aos quais denomina de "bases de mensuração", a saber:

a) custo histórico - "os activos são registados pelas quantias de dinheiro, ou equivalentes de dinheiro pago, ou pelo justo valor do pagamento feito, para os adquirir no momento da sua aquisição";

b) custo corrente - "os activos são registados pela quantia de dinheiro, ou equivalentes de dinheiro, que teria de ser paga se o mesmo ou um activo equivalente fosse correntemente adquirido";

c) valor realizável (de liquidação) - "os activos são registados pela quantia de dinheiro, ou equivalentes de dinheiro, que possa correntemente ser obtida ao vender o activo numa alienação ordenada".;

d) valor presente (actual) - "os activos são registados pelo valor presente descontado dos futuros influxos líquidos de caixa que se espera que o elemento gere no decurso normal dos negócios".

A CNC (2007, §98), na estrutura conceptual do novo SNC, que aprovou em Portugal em julho de 2007, acrescenta ainda um outro critério de valoração que é o justo valor. A CNC (2007, alínea e) do §98) define justo valor como sendo a "quantia pela qual um activo pode ser trocado ou um passivo liquidado, entre partes conhecedoras e dispostas a isso, numa transacção em que não exista relacionamento entre elas". Relativamente ao justo valor, o IASB refere-o nas suas Normas Internacionais de Contabilidade.

No §101 da sua estrutura conceptual, o IASB (1989), acrescenta que, de todas as bases/critérios de mensuração/valoração que apresenta, o mais adoptado pelas empresas é o custo histórico, mas também admite que este pode ser combinado com os restantes.

Em conformidade com isto, o POC em vigor em Portugal, menciona no seu capítulo 5, relativo aos critérios de valorimetria, que tanto as existências como o imobilizado devem ser registados pelo seu custo de aquisição ou de produção. Contudo, permite que, nos casos em que o preço de mercado seja inferior ao custo de aquisição ou de produção, o elemento seja registado pelo seu preço de mercado, admitindo assim uma excepção ao custo histórico.

Contudo, esta não é a única excepção ao custo histórico, preconizada no POC. Na verdade, o custo histórico peca pela sua perda de relevância em períodos de inflação, podendo 
mesmo, nesses períodos, deixar de ser representativo da realidade. Para ultrapassar este problema, o POC admite uma outra excepção ao custo histórico ao permitir que se efectuem reavaliações, quando legalmente autorizadas, e para isso inclui, no seu código de contas, a conta 56 - "Reservas de Reavaliação".

Por outro lado, o justo valor tem ganho importância ao longo dos tempos, uma vez que ultrapassa esta desvantagem do custo histórico, pois tem em conta valores actuais em termos monetários. Os defensores do modelo do justo valor afirmam mesmo que o justo valor fornece uma mensuração mais relevante dos activos do que o custo histórico. Contudo, o justo valor peca em termos de objectividade ao se recorrer, no seu cálculo, a estimações, sendo este aspecto ultrapassado pelo custo histórico, que é objectivo, uma vez que assenta nos valores de aquisição dos activos.

Apesar das desvantagens que o justo valor possa deter, o seu papel enquanto critério de valoração tem ganho crescente importância, sobretudo em resultado da sua menção nas normas contabilísticas, enquanto critério de valoração permitido ou mesmo de aplicação obrigatória. Por exemplo, no âmbito empresarial, o IASB faz menção ao justo valor nas suas Normas Internacionais de Contabilidade (NIC), como no caso das NIC 39 e 40. A NIC 39 (IASB, 1998), que trata acerca dos Instrumentos Financeiros, menciona o justo valor como critério de valoração deste tipo de activos.

No que diz respeito à NIC 40 (IASB, 2000), acerca de propriedades de investimento (IP - Investment Property), esta norma permite que nas valorações posteriores ao reconhecimento inicial destes bens, se opte pelo modelo do custo ou pelo modelo do justo valor; menciona ainda que o modelo escolhido deve ser aplicado a todas as propriedades de investimento da empresa. Para além de referir, em algumas das suas normas, o justo valor enquanto critério de valoração, o IASB no Discussion paper intitulado Measurement Bases for Financial Accounting - Measurement on Initial Recognition (IASB, 2005), emitido em 2005, faz referência a vários critérios de valoração e, entre eles, ao justo valor. Especificamente relativo ao justo valor o IASB tem em mãos um projecto intitulado "Fair Value Measurement”, que tem por objectivo estabelecer um guia simples para a aplicação do justo valor mencionado nas suas normas.

No âmbito desse projecto emitiu, em novembro de 2006, o Discussion paper intitulado Fair value Measurement (IASB, 2006), no qual faz menção da Statement of Financial Accounting Standards (SFAS) 157 do FASB. Esta SFAS 157 (FASB, 2006), emitida pelo FASB em 2006, e intitulada Fair Value Measurements, alarga os estudos relativos ao justo valor e estabelece um guia para a aplicação do justo valor enquanto critério de valoração.

Ao nível da União Europeia, houve necessidade de adaptar as suas Directivas de forma a torná-las coerentes com as Normas Internacionais, pelo que foi emitida a Directiva 2001/65/CE, introduzindo-se o justo valor na valoração de certos activos e passivos financeiros. Para além disto, com o Regulamento (CE) no 1606/2002, a obrigatoriedade de aplicação das NIC, a partir de 1 de janeiro de 2005, para as contas consolidadas das empresas cotadas em bolsa, veio também tornar obrigatória a aplicação do justo valor como critério de valoração de certos activos, sempre que essas normas o definam como tal.

Apesar da introdução, na normalização contabilística, do justo valor enquanto critério de valoração, ganhando este cada vez mais importância, em conformidade com estudos efectuados por diversos autores, a opção pelo modelo do custo histórico ainda continua a ser a preferência da maioria das empresas, continuando a ser este o critério mais utilizado, sobretudo tratando-se da valoração dos seus activos imobilizados corpóreos. 


\subsection{Valoração dos Activos Públicos - especial referência a Portugal}

A questão mais problemática dos activos públicos é, sem dúvida, a sua valoração, sobretudo tratando-se de certos activos que, pelas suas características, não possuem valor de aquisição nem mesmo valor de mercado. Em termos internacionais, nomeadamente nas normas da IFAC, de âmbito público, a valoração dos activos é efectuada, regra geral, distinguindo-se dois momentos distintos, como sejam: a valoração inicial e as valorações posteriores à valoração inicial (segundas e posteriores valorações).

Relativamente à valoração inicial, e para as propriedades de investimento, a IFAC na sua Norma Internacional de Contabilidade para o Sector Público (NICSP) $\mathrm{n}^{\circ} 16$ (IFAC, 2007a, $\S \S 26,27)$ menciona o custo histórico como critério de valoração inicial destes activos; não obstante, admite excepções para aqueles bens que tenham sido adquiridos sem qualquer contrapartida, mencionando que estes devem ser valorados pelo seu justo valor à data de aquisição.

Nas valorações posteriores ao seu reconhecimento inicial, essa mesma norma (IFAC, 2007a, §§ 39-65) menciona que a entidade poderá optar pelo modelo do custo ou pelo modelo do justo valor. Na NICSP $\mathrm{n}^{\circ} 17$ (IFAC, 2007b), relativa aos activos imobilizados corpóreos, a IFAC apresenta, em termos de valoração, um tratamento idêntico ao referido para as propriedades de investimento, mencionando também para as valorações posteriores ao seu reconhecimento inicial, a possibilidade da entidade optar entre o modelo do custo, ou, neste caso, o modelo da reavaliação, considerando para efeitos deste último, o justo valor à data da reavaliação.

Como vimos, apesar da referência ao custo histórico, o justo valor começa a ser também introduzido nas normas internacionais de âmbito público. $\mathrm{Na}$ Contabilidade Pública em Portugal, o POCP, de forma idêntica ao referido relativamente ao POC, apresenta como critério de valoração o custo histórico. Contudo, também admite excepções ao mesmo. Por exemplo, relativamente às reavaliações permitidas no POC, quando legalmente autorizadas, $\mathrm{o}$ POCP também permite que estas sejam efectuadas, preconizando para o efeito a conta 56 Reservas de Reavaliação.

Apesar do POCP ter adoptado como critério de valoração o custo histórico, apresenta algumas situações nas quais se deverão aplicar outros critérios, como por exemplo:

a) os bens cujo preço de mercado é inferior ao custo histórico, deverão ser registados pelo preço de mercado;

b) os activos imobilizados adquiridos a título gratuito, refere o POCP, no ponto 4.1.4. dos critérios de valorimetria, que deverão ser registados pelo "valor resultante da avaliação ou o valor patrimonial definidos nos termos legais ou, caso não exista disposição legal aplicável, o valor resultante da avaliação segundo critérios técnicos que se adeqúem à natureza desses bens". O POCP acrescenta ainda que "na impossibilidade de valorização dos bens, estes deverão ser identificados em anexo e justificada aquela impossibilidade";

c) nas transferências de activos entre entidades sujeitas ao POCP, conforme menciona o ponto 4.1.6. dos critérios de valorimetria, os activos devem ser registados pelo "valor constante nos registos contabilísticos da entidade de origem, salvo se existir valor diferente fixado no diploma que autorizou a transferência ou, em alternativa, valor acordado entre as partes e sancionado por entidade competente". Acrescenta ainda que no caso em que não seja possível aplicar este critério deve ser aplicado o critério definido para os bens adquiridos a título gratuito;

d) os bens de domínio público devem ser valorados, sempre que possível, ao custo de aquisição ou de produção. Quando não seja possível a aplicação destes critérios 
deverão ser valorados seguindo os critérios referidos para as transferências de activos entre entidades, ou na sua impossibilidade de aplicação, os critérios definidos para a valoração dos bens adquiridos a título gratuito.

No que diz respeito ao CIBE, este apresenta nas normas comuns dos inventários de base, mais precisamente no seu art. 31, que os activos imobilizados devem ser valorados consoante: “a) custo de aquisição; b) custo de produção; c) valor resultante da avaliação, nos casos de apreensão, doação, herança, legado, prescrição, reversão, transferência, troca ou outros, nos termos destas instruções". Pelo exposto vemos que o CIBE acrescenta a possibilidade de certos bens serem valorados pelo valor resultante da sua avaliação, o que o POCP preconiza para os activos imobilizados adquiridos a título gratuito e para os restantes activos sujeitos às regras destes.

No âmbito público, o problema da valoração põe-se sobretudo para certos activos públicos que são inalienáveis, e que não possuem um valor de mercado definido, como é o caso de certos bens do património histórico, artístico e cultural, para a valoração dos quais se tem de recorrer ao valor resultante da sua avaliação. Contudo, mesmo a avaliação destes bens é muitas vezes ambígua e subjectiva, o que implica que por vezes sejam valorados por valor zero, ou pelo valor pelo qual estão segurados, conforme mencionado no $\mathrm{n}^{\circ} 2$ do art. 31 do CIBE, ou chegando mesmo a não serem evidenciados nas demonstrações financeiras.

Em conformidade com o Anuário Financeiro dos Municípios Portugueses - 2004 (CARVALHO et al., 2006, p. 88), dos 289 municípios analisados, 161 têm no seu activo bens de domínio público mas não têm qualquer valor no património histórico, artístico e cultural. No Anuário relativo ao ano de 2005 (CARVALHO et al., 2007, p.114), de 307 municípios analisados, 174 não apresenta qualquer valor no património artístico e cultural, o que representa 56,5\% do total dos municípios existentes (308 municípios). Estes números parecem-nos bastante relevantes "quando todos os municípios têm no seu património este tipo de bens de domínio público" (CARVALHO et al., 2007, p. 115).

$\mathrm{O}$ facto de muitos desses bens não estarem contabilizados e valorados (e muitas vezes não referidos, no anexo às demonstrações financeiras, como bens não avaliados) faz com que o peso dos bens de domínio público desses municípios face ao total do seu activo se apresente aquém dos valores reais existentes. Conforme Carvalho et al. (2007, p. 146), no ano de 2005, de 307 municípios analisados, apenas 129 apresentaram, no anexo às demonstrações financeiras (ponto 8.2.14 do POCAL), informação relativa aos bens não avaliados.

Em suma, dizemos assim que, apesar dos diversos critérios de valoração apresentados na estrutura conceptual do IASB (1989), ou mesmo, mais especificamente no âmbito público, nas normas da IFAC, no POCP e no CIBE, o certo é que muitas entidades públicas continuam a sentir dificuldades na valoração de alguns dos seus activos, mais precisamente na aplicação do critério do custo histórico a certos activos públicos, incorporando-os muitas vezes no Balanço com valor nulo, ou não lhes fazendo qualquer menção.

Estas evidências demonstram claramente a necessidade que sejam emitidas normas de valoração específicas, sobretudo, para aqueles activos públicos com maiores dificuldades na sua valoração; e também, com vista ao alcance de uma maior comparabilidade da informação a nível internacional, que se proceda à adaptação das NICSP, da IFAC, à Contabilidade Pública em Portugal.

\section{CONCLUSÃO}

Partindo de uma Contabilidade Pública tradicional com objectivos ligados ao controlo da legalidade e execução do orçamento, e que aplicava uma contabilidade orçamental, chegamos actualmente, e em resultado de uma reforma da Contabilidade Pública em Portugal, a uma Contabilidade Pública assente em três sistemas de contabilidade, a orçamental, a 
patrimonial e a analítica, com objectivos ligados ao fornecimento de informação útil para a tomada de decisões. Da tradicional Conta de Gerência passamos para a elaboração de demonstrações financeiras mais elaboradas, como por exemplo, o Balanço, a Demonstração de Resultados e os Mapas de Execução Orçamental.

Com a introdução da contabilidade patrimonial e, consequentemente, com o surgimento do Balanço na Contabilidade Pública, aparece a "figura de activo", começando a desempenhar um importante papel na determinação do valor e composição do património. $\mathrm{O}$ ponto central da questão reside em determinar quais os elementos que poderão ser classificados como activos. Para responder a esta questão e limitar o campo de acção de quem os classifica, torna-se necessário que seja criada uma estrutura conceptual para a Contabilidade Pública em Portugal, que defina o conceito dos elementos das demonstrações financeiras, os critérios para o seu reconhecimento, bem como os critérios para a sua valoração.

Classificar um elemento como activo implica que, em primeiro lugar, preencha o seu conceito e, em segundo lugar, os seus critérios de reconhecimento. Podemos dizer que, no âmbito público, preenche o conceito de activo todo o recurso que seja controlado pela entidade, como resultado de acontecimentos passados e do qual se espere que possa ser utilizado na prestação futura de serviços públicos ou na obtenção de rendimentos.

No âmbito público, os benefícios económicos futuros resultantes de um activo devem ser vistos não (apenas) em termos de rendimentos que o mesmo proporcione, mas também, e sobretudo, em função da capacidade do activo continuar a prestar serviços no futuro. É neste aspecto que o conceito de activo público se distingue do conceito de activo no âmbito empresarial.

Para que um elemento seja reconhecido como activo, além de ser necessário que preencha o conceito de activo, deve também preencher os requisitos da relevância para a entidade pública em causa e da fiabilidade da sua valoração. Dizemos que um elemento é relevante para a entidade pública quando seja provável a sua aplicação no alcance dos objectivos da entidade e na prestação de serviços.

Quanto à sua valoração, deveremos atender aos diferentes critérios de valoração apresentados nas normas nacionais e internacionais. O critério de valoração que mais usualmente se aplica é o critério do custo histórico que prima pela sua fiabilidade, mas que peca pela sua relevância sobretudo em períodos de inflação. Contudo, o justo valor tem ganho importância ao longo dos tempos em virtude da sua relevância, se bem que peca em termos de objectividade. Na verdade, a escolha de um ou outro critério de valoração vai depender das características do activo em causa e do papel que esse desempenha.

Uma vez preenchido o conceito de activo e cumpridos os critérios para o seu reconhecimento, um elemento deverá ser classificado como activo de uma entidade pública, constando assim do seu balanço. Contudo, um elemento uma vez reconhecido como activo não está reconhecido para sempre, basta que deixe de preencher uma das condições já referidas para deixar de constar no balanço da entidade em causa.

Em virtude da complexidade destes conceitos e do facto de um elemento implicar necessariamente que se atenda aos conceitos de outros elementos, é evidente a necessidade de se definirem também os restantes elementos de uma estrutura conceptual, enquanto suporte teórico para a prática contabilística.

\section{REFERÊNCIAS}

ACCOUNTING STANDARDS BOARD (ASB). Revised Exposure Draft - Statement of Principles for Financial Reporting. London: ASB, 1999. 
ACCOUNTING STANDARDS BOARD (ASB). Exposure Draft - Statement of Principles for Financial Reporting. London: ASB, 1991.

ASOCIACIÓN ESPAÑOLA DE CONTABILIDAD Y ADMINISTRACIÓN DE EMPRESAS (AECA). El marco conceptual para la información financiera de las administraciones públicas. Serie Principios Contables, Documentos AECA. Madrid: AECA, 2001.

ASOCIACIÓN ESPAÑOLA DE CONTABILIDAD Y ADMINISTRACIÓN DE EMPRESAS (AECA). El Marco conceptual para la información financiera. Serie Principios Contables, Documentos AECA. Madrid: AECA, 1999.

BRUSCA ALIJARDE, I. La diversidad de los sistemas contables públicos en el contexto internacional. In: JORNADA DE TRABAJO SOBRE CONTABILIDAD PÚBLICA, 6., Oviedo, 2000. Anais ... Oviedo: Universidad de Oviedo, 2000.

CADASTRO E INVENTÁRIO DOS BENS DO ESTADO (CIBE). Portaria $\mathbf{n}^{\mathbf{0}} \mathbf{6 7 1 / 2 0 0 0}$, de 17 de Abril.

CARDÃO-PITO, Tiágo. Several contributions of the intangible flow theory for the concepts of asset and of intangible asset. In: ANNUAL CONGRESS EUROPEAN ACCOUNTING ASSOCIATION, 30., Lisboa, 2007. Anais ... Lisboa, 2007.

CARVAlHO, João Baptista da Costa; ALVES, Jorge M. Afonso. CIBE - Comentado. Lisboa: Publisher Team, 2006.

CARVALHO, João; FERNANDES, Maria José; CAMÕES, Pedro; JORGE, Susana. Anuário financeiro dos municípios Portugueses - 2004. Lisboa, 2006.

CARVALHO, João; FERNANDES, Maria José; CAMÕES, Pedro; JORGE, Susana. Anuário Financeiro dos Municípios Portugueses - 2005. Lisboa, 2007.

COMISSÃO DE NORMALIZAÇÃO CONTABILÍSTICA (CNC). Estrutura Conceptual do Sistema de Normalização Contabilística (SNC). Lisboa: CNC, 2007.

COMUNIDADE EUROPEIA (CE). Directiva 2001/65/CE, de 27 de setembro de 2001.

COMUNIDADE EUROPEIA (CE). Regulamento n⿳ 1606/2002, do Parlamento Europeu e do Conselho, de 19 de julho 2002.

FINANCIAL ACCOUNTING STANDARDS BOARD (FASB). Statement of Financial Accounting Concepts $n^{\mathbf{0}} \mathbf{5}$ - Recognition and Measurements in Financial Statements of Business Enterprises. Connecticut: FASB, 1984.

FINANCIAL ACCOUNTING STANDARDS BOARD (FASB). Statement of Financial Accounting Concepts $\mathbf{n}^{\mathbf{0}} 6$ - Elements of Financial Statements. Connecticut: FASB, 1985.

FINANCIAL ACCOUNTING STANDARDS BOARD (FASB). Statement of Financial Accounting Standards n⿳ 157 - Fair Value Measurements, Connecticut: FASB, 2006.

FREITAS, Guilhermina. Os elementos das demonstrações financeiras públicas: algumas particularidades. In: CONGRESSO DE CONTABILIDADE E AUDITORIA, 8., Aveiro, 2000. Anais ... Aveiro: ISCAA, 2000.

FREITAS, Guilhermina. Ajustamentos ao modelo contabilístico na ausência de finalidade lucrativa. In: CONGRÉS ACCID, 2., Barcelona, 2007. Anais ... Barcelona, 2007. 
GOVERNMENT ACCOUNTING STANDARDS BOARD (GASB). Statement no 11 Measurement Focus and Basis of Accounting - Governmental Fund Operating Statements. GASB, 1990.

INTERNATIONAL ACCOUNTING STANDARDS BOARD (IASB). Estrutura Conceptual para a preparação e apresentação das demonstrações financeiras. IASB, 1989.

INTERNATIONAL ACCOUNTING STANDARDS BOARD (IASB). Norma Internacional de Contabilidade $n^{0} 39$ - Financial Instruments: recognition and measurement. IASB, 1998.

INTERNATIONAL ACCOUNTING STANDARDS BOARD (IASB). Norma Internacional de Contabilidade $\mathbf{n}^{\mathbf{0}} 40$ - Investment Property. IASB, 2000.

INTERNATIONAL ACCOUNTING STANDARDS BOARD (IASB). Discussion Paper: Measurement Bases for Financial Accounting - Measurement on Initial Recognition. IASB, 2005.

INTERNATIONAL ACCOUNTING STANDARDS BOARD (IASB). Discussion Paper: Fair Value Measurements, part 1, 2. IASB, 2006.

INTERNATIONAL FEDERATION OF ACCOUNTANTS (IFAC). Norma Internacional de Contabilidade para o Sector Público $n^{0} 1$ - Apresentação das Demonstrações Financeiras. IFAC, 2000.

INTERNATIONAL FEDERATION OF ACCOUNTANTS (IFAC). Norma Internacional de Contabilidade para o Sector Público no 16 - Investment Property. IFAC, 2007a.

INTERNATIONAL FEDERATION OF ACCOUNTANTS (IFAC). Norma Internacional de Contabilidade para o Sector Público n¹7 - Property, Plant and Equipment. IFAC, 2007b.

PORTUGAL. Lei no 91/2001, Lei de Enquadramento Orçamental, de 20 de Agosto de 2001.

PORTUGAL. Lei $\mathbf{n}^{\mathbf{0}}$ 6/91, Lei de Enquadramento Orçamental, de 20 de fevereiro de 1991.

PORTUGAL. Lei nº 8/90, Lei de Bases da Contabilidade Pública, de 20 de fevereiro de 1990.

PORTUGAL. Decreto-Lei $\mathbf{n}^{\mathbf{0}} \mathbf{1 2 / 2 0 0 2}$, Plano Oficial de Contabilidade das Instituições do Sistema de Solidariedade e Segurança Social (POC-ISSS), de 25 de janeiro de 2002.

PORTUGAL. Decreto-Lei no 54 - A/99, Plano Oficial de Contabilidade das Autarquias Locais (POCAL), de 22 de fevereiro 1999.

PORTUGAL. Decreto-Lei $\mathbf{n}^{\mathbf{0}}$ 232/97, Plano Oficial de Contabilidade Pública (POCP), de 3 de setembro de 1997.

PORTUGAL. Decreto-Lei $\mathbf{n}^{\mathbf{0}}$ 155/92, Regime da Administração Financeira do Estado, de 28 de julho de 1992.

PORTUGAL. Decreto-Lei $\mathbf{n}^{\mathbf{0}}$ 410/89, Plano Oficial de Contabilidade (POC), de 21 de novembro de 1989, com as alterações resultantes do Decreto-Lei $n^{\circ}$ 238/91, de 2 de julho de 1991, e do Decreto-Lei n ${ }^{\circ}$ 35/2005, de 17 de fevereiro de 2005.

PORTUGAL. Portaria n⿳ 898/2000, Plano Oficial de Contabilidade para o Ministério da Saúde (POC-MS), de 28 de setembro de 2000.

PORTUGAL. Portaria $\mathbf{n}^{\mathbf{0}} \mathbf{7 9 4} / \mathbf{2 0 0 0}$, Plano Oficial de Contabilidade para o Sector da Educação (POC-EDU), de 20 de setembro de 2000. 
PORTUGAL. Resolução no 1/93, do Tribunal de Contas, de 1993.

RUA, Susana Catarino; CARVALHO, João Baptista da Costa. Contabilidade pública: estrutura conceptual. Lisboa: Publisher Team, 2006.

SANTOS, Luís Lima. A Estrutura Conceptual da Contabilidade em Portugal. In: IX CONGRESSO DE CONTABILIDADE, 2002. Porto: ISCAP, Porto, 2002.

YEBRA CEMBORAIN, Raúl Óscar. Definición y reconocimiento de los elementos de los estados financieros. In: TUA, Jorge (Coord.). El marco conceptual para la información financiera: análisis y comentarios. AECA, 2000. pp. 195-224. 